\title{
Singular v Dual inhibition of SNF2L and its isoform, SNF2LT, have similar effects on DNA Damage but opposite effects on the DNA Damage Response, Cancer Cell Growth Arrest and Apoptosis
}

\author{
Yin $\mathrm{Ye}^{1}$, Yi Xiao², Wenting Wang2, Jian-Xin Gao², Kurtis Yearsley², Quintao Yan² \\ and Sanford H. Barsky ${ }^{1,3,4}$ \\ ${ }^{1}$ Department of Pathology, University of Nevada School of Medicine, Reno, NV \\ 2 Department of Pathology, Ohio State University College of Medicine, Columbus, $\mathrm{OH}$ \\ ${ }^{3}$ The Whittemore-Peterson Institute, Reno, NV \\ ${ }^{4}$ Nevada Cancer Institute, Las Vegas, NV \\ Correspondence to: Sanford H. Barsky, email: sbarsky@ medicine.nevada.edu \\ Keywords: SNF2L, DNA damage, SNF2LT, NURF \\ Received: April 11, 2012, Accepted: April 28, 2012, \\ Published: May 9, 2012
}

Copyright: (C) Ye et al. This is an open-access article distributed under the terms of the Creative Commons Attribution License, which permits unrestricted use, distribution, and reproduction in any medium, provided the original author and source are credited.

\section{ABSTRACT:}

SNF2L, an ATPase chromatin remodeling gene nearly ubiquitously expressed in diverse tissues, cancers, and derived cell lines, contributes to the chromatin remodeling complex that facilitates transcription. Because of this near ubiquitous expression, it has not been exploited as a cancer therapeutic target. However, in a recent study, we found that highly malignant cancer cells, although expressing SNF2L at similar levels as their normal counterparts, were sensitive to its knockdown. Only the highly malignant (HM) lines showed significant growth inhibition, DNA damage, a DNA damage response, and phosphorylation of checkpoint proteins and marked apoptosis. In studying SNF2L, we discovered a novel truncated isoform, SNF2LT which, when compared to full length SNF2L, lacked three important domains: HAND, SANT and SLIDE. Although truncated isoforms usually have antagonistic functions to their parental molecule, here SNF2LT knockdown had similar effects to the knockdown of its parental molecule, SNF2L, of inducing DNA damage, a DNA damage response, cell cycle arrest and apoptosis selectively in cancer cell lines. However dual SNF2L and SNF2LT knockdown, while inducing DNA damage, did not result in a DNA damage response, a cell cycle arrest and apoptosis. In fact $\mathrm{HM}$ lines subjected to dual knockdown paradoxically exhibited sustained cell growth. Our findings indicate that the ratio of SNF2L to its isoform tightly regulates the cancer cell's response to DNA damage. Cancer cell lines which endogenously express low levels of both SNF2L and its isoform mimic the situation of dual knockdown and permit DNA damage which is allowed to propagate unchecked.

\section{INTRODUCTION}

Aberrant gene function and altered patterns of gene expression are key features of cancer. An explosion of data indicating the importance of epigenetic processes, especially those resulting in the silencing of key regulatory genes, has led to the realization that genetics and epigenetics cooperate at all stages of cancer development [1-5]. Epigenetic modifications fall into two main categories: DNA methylation and histone modifications [6-10]. The processes of covalent histone modification and DNA methylation couple with chromatin remodeling by ATP-dependent remodeling machines to obtain efficient transcriptional regulation, DNA replication and DNA-damage repair [11-15]. Emerging data have shown that ATPase-dependent remodeling enzymes all act in the context of multisubunit complexes, which adds an additional layer of fine-tuned specificity in ATP-dependent chromatin remodeling [16-20].

SNF2L (SMARCA1), an ATPase chromatin remodeling gene nearly ubiquitously expressed in diverse tissues, cancers, and derived cell lines, contributes 
A

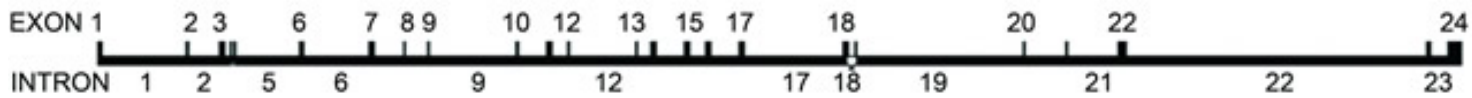

B

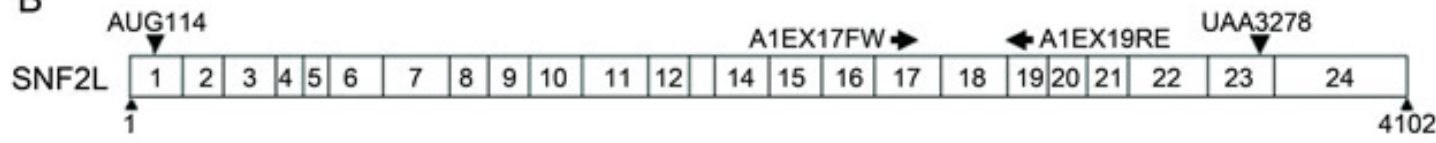

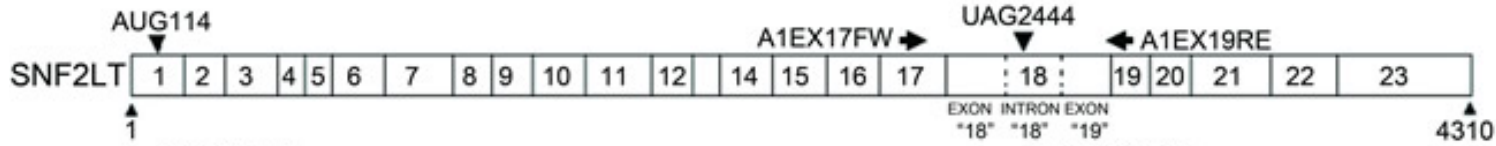
SNF2LFW $\mathrm{SNF} 2 \mathrm{LTFW} \rightarrow$ SNF2LRE

C

SNF2L
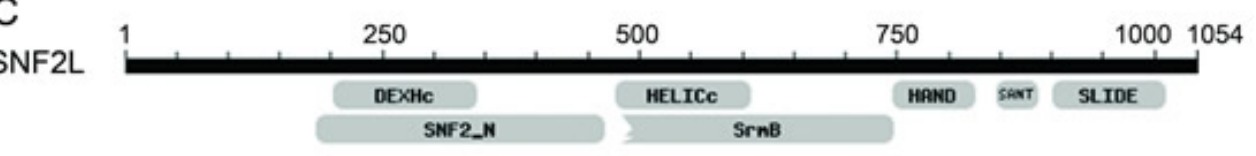

\section{HELICe}

1

250

500

HAND Seart SLIDE

SNF2LT

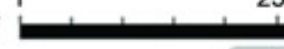

DEXHc

SMF 2_N

\section{HELICC}

D

1 MEQDTAAVAATVAAADATATIVVIEDEQPGPSTSQEEGAAAAATEATAATEKGEKKKEKNVSSFQLKLAAKAPKSEKEMDPEYEEKMKAD 1 MEQDTAAVAATVAAADATATIVIIEDEQPGPSTSQEEGAAAAATEATAATEKGEKKKEKNVSSFQLKLAAKAPKSEKEMDPEYEEKMKAD

1 MEQDTAAVAATVAAADATATIVIIEDEQPGPSTSQEEGAAAAATEATAATEKGEKKKEKNVSSFQLKLAAKAPKSEKENDPEYEEKMKAD

91 RAKRFEFLLKQTELFAHFIQPSAQKSPTSPLNMKLGRPRIKKDEKQSLISAGDYRHRRTEQEEDEELLSESRKTSNVCIRFEVSPSYVKG 91 RAKRFEFLLLQTELFAHFIQPSAQKSPTSPLNMKLGRPRIKKDEKQSLISAGDYRHRRTEQEEDEELLSESRKTSNVCIRFEVSPSYVKG 91 RAKRFEFLLKQTELFAHFIQPSAQKSPTSPLNMKLGRPRIKKDEKQSLISAGDYRHRRTEQEEDEELLSESRKTSNVCIRFEVSPSYVKG

181 GPLRDYQIRGLNWLISLYENGVNGILADEMGLGKTLQTIALLGYLKHYRNIPGPHMVLVPKSTLHNWMNEFKRWVPSLRVICFVGDKDAR 181 GPLRDYQIRGLNWLISLYENGVNGILADEMGLGKTLQTIALLGYLKHYRNIPGPHMVLVPKSTLHNWMNEFKRWVPSLRVICFVGDKDAR 181 GPLRDYQIRGLNWLISLYENGVNGILAD-_-_N

SNF2LT SNF2L-a SNF2L-b

271 AAFIRDEMMPGEWDVCVTSYEMVIKEKSVFKKFHWRYLVIDEAHRIKNEKSKLSEIVREFKSTNRLLLTGTPLQNNLHELWALLNFLLPD 271 AAFIRDEMMPGEWDVCVTSYEMVIKEKSVFKKFHWRYLVIDEAHRIKNEKSKLSEIVREFKSTNRLLLTGTPLQNNLHELWALLNFLLPD 250 AAFIRDEMMPGEWOVCVTSYEMVIKEKSVFKKFHWRYLVIDEAHRIKNEKSKLSEIVREFKSTNRLLLTGTPLQNNLHELWALLNFLLPD

361 VFNSADDFDSWFDTKNCLGDOKLVERLHAVLKPFLLRRIKTDVEKSLPPKKEIKIYLGLSKMQREWYTKILMKDIDVLNSSGKMDKMRLL 361 VFNSADDFDSWFDTKNCLGDQKLVERLHAVLKPFLLRRIKTDVEKSLPPKKEIKIYLGLSKMQREWYTKILMKDIDVLNSSGKMDKMRLL 340 VFNSADDFDSWFDTKNCLGDQKLVERLHAVLKPFLLRRIKTDVEKSLPPKKEIKIYLGLSKMQREWYTKILMKDIDVLNSSGKMDKMRLL

451 NILMQLRKCCNHPYLFDGAEPGPPYTTDEHIVSNSGKMVVLDKLLAKLKEQGSRVLIFSQMTRLLDILEDYCWRGYEYCRLDGQTPHEE 451 NILMQLRKCCNHPYLFDGAEPGPPYTTDEHIVSNSGKMVVLDKLLAKLKEQGSRVLIFSQMTRLLDILEDYCMWRGYEYCRLDGQTPHEE 430 NILMQLRKCCNHPYLFDGAEPGPPYTTDEHIVSNSGKMVVLDKLLAKLKEQGSRVLIFSQMTRLLDILEDYCMWRGYEYCRLDGQTPHEE

541 RE-- - EAIEAFNAPNSSKFIFMLSTRAGGLGINLASADWILYDSOWNPQVDLQAMDRAHRIGQKKPVRVFRLITDNTVEE 541 REDKFLEVEFLGQREAIEAFNAPNSSKFIFMLSTRAGGLGINLASADVVILYDSOWNPQVDLQAMDRAHRIGQKKPVRVFRLITDNTVEE 520 REDKFLEVEFLGQREAIEAFNAPNSSKFIFMLSTRAGGLGINLASADVVILYDSDWNPQVDLQAMDRAHRIGQKKPVRVFRLITDNTVEE

SNF2LT SNF2L-a SNF2L-b

619 RIVERAEIKLRLDSIVIQQGRLIDQQSNKLAKEEMLQMIRHGATHVFASKESELTDEDITTILERGEKKTAEMNERLQKMGESSLRNFRM 631 RIVERAEIKLRLDSIVIQQGRLIDQQSNKLAKEEMLQMIRHGATHVFASKESELTDEDITIILERGEKKTAEMNERLQKMGESSLRNFRM 610 RIVERAEIKLRLDSIVIQQGRLIDQQSNKLAKEEMLQMIRHGATHVFASKESELTDEOITIILERGEKKTAEMNERLQKMGESSLRNFRM

SNF2LT SNF2L-a SNF2L-b

709 DIEQSLYKFEGEDYREKQKLGMVEWIEPPKRERKANYAVDAYFREALRVSEPKIPK 721 DIEQSLYKFEGEDYREKQKLGMVEWIEPPKRERKANYAVDAYFREALRVSEPKIPKAPRPPKQPNVQOFQFFPPRLFELLEKEILYYRKT 700 DIEQSLYKFEGEDYREKQKLGMVEWIEPPKRERKANYAVDAYFREALRVSEPKIPKAPRPPKQPNVQOFQFFPPRLFELLEKEILYYRKT

765

811 IGYKVPRNPDIPNPALAQREEQKKIDGAEPLTPEETEEKEKLLTQGFTNWTKRDFNQFIKANEKYGRDDIDNIAREVEGKSPEEVMEYSA 790 IGYKVPRNPDIPNPALAQREEQKKIDGAEPLTPEETEEKEKLLTQGFTNWTKRDFNQFIKANEKYGRDDIDNIAREVEGKSPEEVMEYSA

765 -

901 VFWERCNELQDIEKIMAQIERGEARIQRRISIKKALDAKIARYKAPFHQLRIQYGTSKGKNYTEEEDRFLICMLHKMGFDRENVYEELRQ 880 VFWERCNELQDIEKIMAQIERGEARIQRRISIKKALDAKIARYKAPFHQLRIQYGTSKGKNYTEEEDRFLICMLHKMGFDRENVYEELRQ

776

991 CVRNAPQFRFDWFIKSRTAMEFQRRCNTLISLIEKENMEIEERERAEKKKRATKTPMVKFSAFS

970 CVRNAPQFRFDWFIKSRTAMEFQRRCNTLISLIEKENMEIEERERAEKKKRATKTPMVKFSAFS

776
1054
1033

\section{SNF2LT}

SNF2L-a

SNF2L-b

SNF2LT

SNF2L-a

SNF2L-b

SNF2LT

SNF2L-a

SNF2L-b

SNF2LT

SNF2L-a

SNF2L-b

Figure 1: Comparisons of SNF2L (SMARCA1) with SNF2LT (A1IS). A, the exon/intron map of SNF2L/SNF2LT is depicted. B, the RT-PCR strategy to amplify both SNF2L and SNF2LT is depicted. C, the structural/functional domains of SNF2L are compared to those of SNF2LT. D, detailed comparisons of intron and exon sequences present in SNF2L (SMARCA1) and SNF2LT (A1IS). Two variants of parental SNF2L (SNF2L-a and SNF2L-b) are depicted. Each experiment was performed in triplicate and repeated at least four times. 
to the chromatin remodeling complex that facilitates transcription. Because of this near ubiquitous expression, it has not been exploited as a cancer therapeutic target. However, in a recent study [21], we found that cancer cells, although expressing SNF2L at similar levels as their normal counterparts, were exquisitely sensitive to its knockdown. This was not observed when its imitation SWI ortholog, SNF2H, was inhibited. SNF2L siRNA inhibition using two different siRNAs separately reduced SNF2L transcript levels and protein in both normal and cancer lines, but only the cancer lines showed DNA damage, a DNA damage response, phosphorylation of cell cycle checkpoint proteins, significant growth inhibition and marked apoptosis.

SNF2L, the ISWI family member of the SNF2 ATPase superfamily in humans, is one subunit of the ATPdependent chromatin complex hNURF. The other two subunits of hNURF are BPTF and RbAP46/RbAP48 [22]. The data have shown that NURF regulates expression of homeotic genes, modulates Wnt-signaling, and affects higher-order chromatin structure; in vitro NURF catalyzes formation of regularly spaced nucleosomal arrays and facilitates transcription activation $[23,24]$.

The SNF2L gene encodes a 1054-amino acid protein with six putative conserved domains: SNF2_L, DEXHc, HELICc, HAND, SANT and SLIDE [25]. The SNF2_N (SNF2 family N-terminal domain) (186-466 aa) is found in proteins involved in a variety of processes including transcription regulation, DNA repair, DNA recombination, and chromatin unwinding. DEXHc contains the ATPbinding region and is found in a diverse family of proteins involved in ATP-dependent DNA or RNA unwinding. HELICc (Helicase superfamily c-terminal domain) (477$620 \mathrm{aa}$ ) is found in a wide variety of helicases and helicase related proteins; it utilizes the free energy from nucleoside triphosphate hydrolysis to fuel their translocation along DNA, unwinding the duplex in the process. HAND (the HAND domain) (758-838 aa) adopts a secondary structure consisting of four alpha helices, three of which (H2, H3, H4) form an L-like configuration. The domain confers DNA and nucleosome binding properties to the protein. Tandem copies of the SANT ('SW13, ADA2, N-CoR and TFIIIB' DNA-binding domains) domain bind telomeric DNA tandem repeats as part of the capping complex. Binding is sequence dependent for repeats which contain the $\mathrm{G} / \mathrm{C}$ rich motif $\left[\mathrm{C}_{2-3} \mathrm{~A}(\mathrm{CA})_{1-6}\right]$. The domain is also found in regulatory transcriptional repressor complexes where it also binds DNA. The SLIDE domain (913-1022 aa) adopts a secondary structure comprising a main core of three alpha-helices. It has a role in DNA binding, contacting DNA target sites similar to c-Myb repeats or homeodomains. SANT and SLIDE domains also mediate interaction with unmodified histone tails and linker DNA.

In studying SNF2L, we discovered a novel truncated


Figure 2: SNF2L and SNF2LT expression by RT-PCR in different normal human tissues, cancers and cell lines. A, expression of SNF2L and SNF2LT by RT-PCR in different human normal tissues. SNF2L was nearly ubiquitously expressed in human normal tissues with especially high expression in ovary and testis; SNF2LT was similarly expressed though only at a molar fraction of the level of SNF2L. B, both SNF2L as well as SNF2LT were expressed in all tested human cancer tissues. C, both SNF2L and SNF2LT were also expressed in nearly all human cancer cell lines with the exception of MARY-XT (xenograft tumor) and in vitro derived spheroids (MARY-X SP), both derived from a patient with inflammatory breast cancer $(26,27)$. ACTB served as housekeeping control. Each experiment was performed in triplicate and repeated at least four times. 
isoform, SNF2LT, which, when compared to full length SNF2L lacked three important domains: HAND, SANT and SLIDE. Because SNF2L knockdown had such a selective effect on highly malignant (HM) lines [21) and the presence of an altered functional splice variant might suggest an additional level of biological complexity in the regulation of the action of SNF2L, we decided to study both molecules and their relationship in detail in the present study.

\section{MATERIALS AND METHODS}

\section{Reagents and antibodies}

All antibodies used were rabbit polyclonal unless otherwise indicated and included an antibody to SNF2L (SMARCA1; ab37003; Abcam, Inc.). Antibodies used for detection of DNA damage were obtained from the DNA Damage Antibody Sampler (Cell Signaling Technology, Inc., Danvers, MA), which included Phospho-ATR (Ser428), Phospho-ATM (Ser1981) mouse monoclonal antibody (mAb), Phospho-BRCA1 (Ser1524), PhosphoCHK1 (Ser296), Phospho-CHK2 (Thr68), PhosphoHistone H2AX (Ser139), and Phospho-p53 (Ser15; 16G8) mouse mAb. p53 (7F5) rabbit mAb and $\beta$-actin (13E5) rabbit $\mathrm{mAb}$ were also used (Cell Signaling Technology, Inc.). Antibodies for detection of cell cycle checkpoints used the Cell Cycle/Checkpoint Sampler kit (Cell Signaling Technology, Inc.), which included Phospho-cdc2 (Tyr15) and Phospho-Rb (Ser795). Additional antibodies that recognized total protein levels of the respective DNA damage proteins (CHK1, CHK2, BRCA1, ATR, and $\mathrm{H} 2 \mathrm{AX}$ ) and cell cycle checkpoint proteins (cdc2, $\mathrm{Rb}$, mouse $\mathrm{mAb}$ ) were also obtained (Cell Signaling Technology, Inc.). Secondary antibodies and Western blotting substrates were obtained (Pierce Biotechnology, Inc., Rockford, Il). Human tumor total RNAs and the FirstChoice Human Total RNA Survey Panel were also used (Ambion, Inc., Austin, TX).

\section{Cell lines and human tissues}

All the cell lines were grown under standard conditions in DMEM with 10\% fetal bovine serum with
A
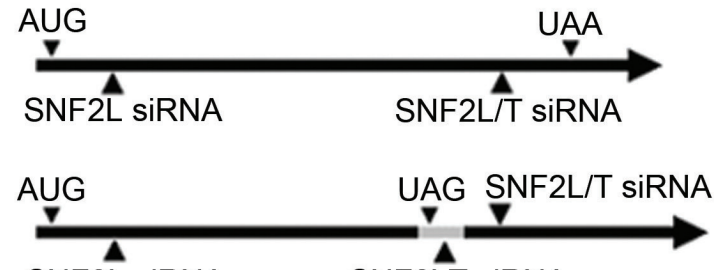

SNF2L SiRNA

C

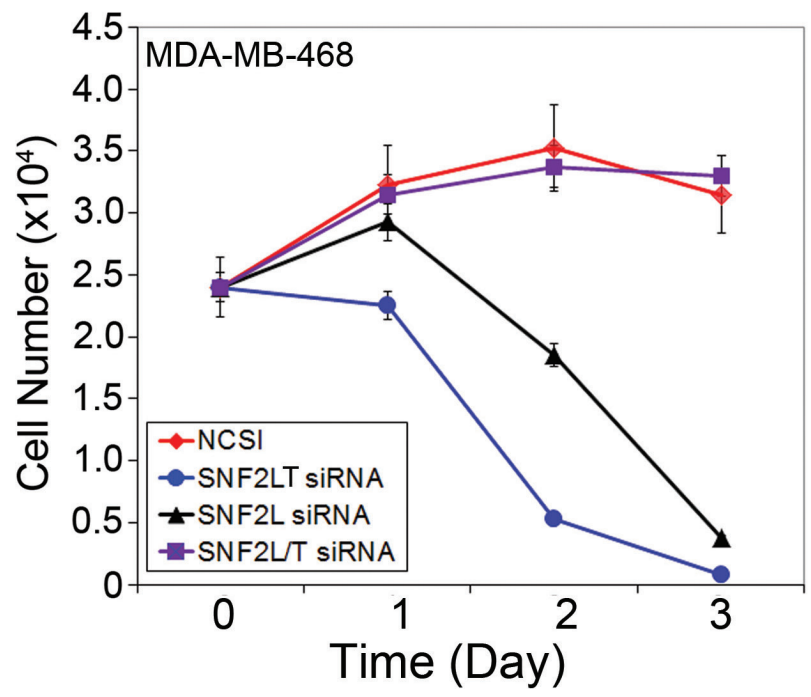

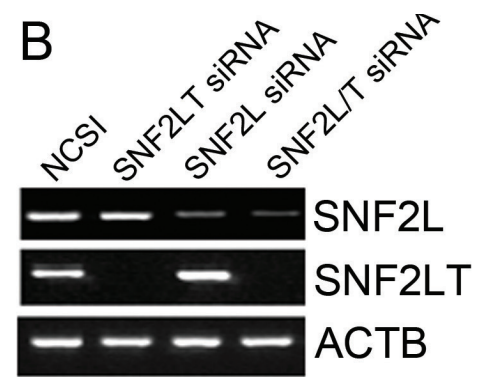

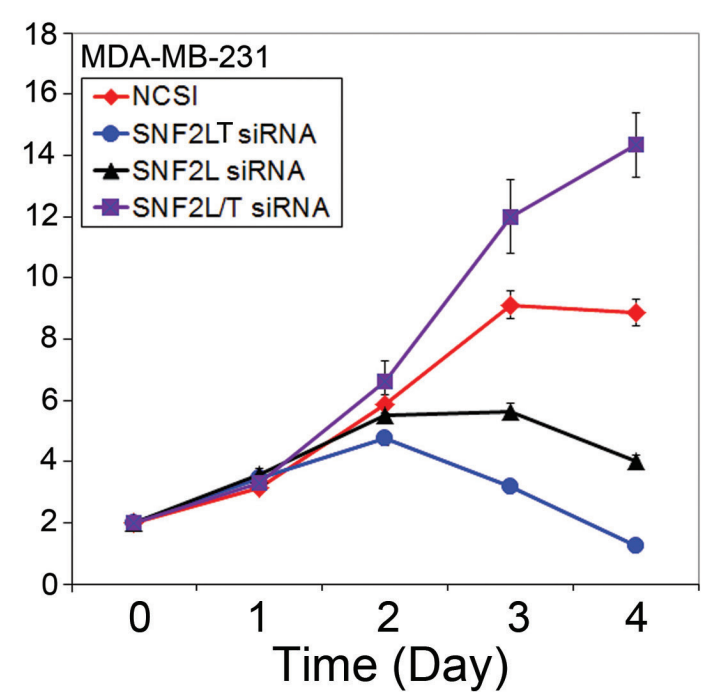

Figure 3: Singular v dual knockdown of SNF2L and SNF2LT and cell growth. A, siRNAs and their targeted areas are depicted. B, SNF2L siRNA (12578) selectively knocked down SNF2L; SNF2LT siRNA (A1IS) selectively knocked down SNF2LT; and SNF2L/T siRNA (12667) knocked down both SNF2L as well as its isoform, SNF2LT. siRNA (NCSI) (RNAi-neg) was used as the negative control. ACTB served as housekeeping gene. C, singular knockdown of either SNF2L or SNF2LT significantly inhibited the growth of HM lines (MDA-MB-468 and MDA-MB-231). Dual knockdown of SNF2L as well as SNF2LT, however, was permissive of growth in HM lines. Each experiment was performed in triplicate and repeated at least four times. 
the exception of the fibroblast lines, which were grown in MEM- $\alpha$ medium with $10 \%$ fetal bovine serum, and the myoepithelial lines, which were grown in KSFM with supplements (Life Technologies, Inc., Grand Island, NY). All lines, unless otherwise indicated, were obtained from a single source (American Type Culture Collection, Manassas, VA) and were human and consisted of the following: HM: estrogen receptor-negative breast cancer lines (MDA-MB-231, MDA-MB-468), Her-2/ neu-amplified breast cancer lines (HCC202, HTB20; HTB27), an inflammatory breast cancer xenograft, MARY-X, established by us [26,27], a cervical squamous cell carcinoma (HeLa), a rhabdomyosarcoma (RB), a leiomyosarcoma (SKLMS-1), and an osteosarcoma (U2OS) line; NU: three fibroblast lines including dermal HDF and pulmonary HLF, (gifts of Dr. Issekutz, Dalhousie University, Halifax, Canada) and skin OSU-2 (a gift of Altaf Wani, Ohio State University, Columbus, $\mathrm{OH}$ ), a mammary epithelial line (HMEC; Clonetics), and the nontumorigenic estrogen receptor-negative MCF-10A line; and benign or LG lines and xenografts: HMS-X and HMS-1, derived by us from a benign human myoepithelial salivary gland tumor and HMS-3X, HMS-4X, and HMS$6 \mathrm{X}$, derived from other benign matrix-secreting human

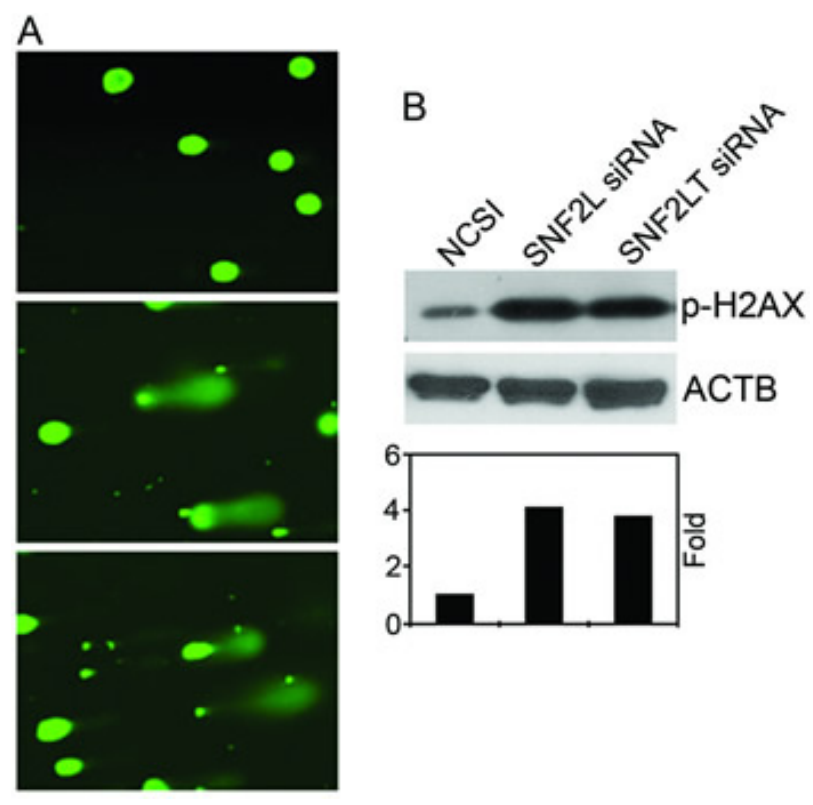

Figure 4: Singular $v$ dual knockdown of SNF2L and SNF2LT and DNA damage. A, MDA-MB-468 cells were transfected with SNF2L siRNA, SNF2L siRNA or NCSI. 48 hours after transfection, DNA damage was analyzed by the Comet assay and the results showed damaged DNA (the comet tail) outside the nucleus after treatment of SNF2LT siRNA (lower panel), SNF2L siRNA (middle panel) compared to undamaged DNA in the cells treated with NCSI (upper panel). $\mathrm{B}$, the surrogate DNA damage gene, $\mathrm{p}-\mathrm{H} 2 \mathrm{AX}$ showed increased expression following either SNF2L or SNF2LT knockdown (upper panel) and increased fold expression of p-H2AX (lower panel). Each experiment was performed in triplicate and repeated at least four times. myoepithelial tumors from salivary gland, breast and pulmonary sources [28], and the estrogen receptorpositive breast carcinoma MCF-7. All the lines were grown under standard conditions.

Human tissues (normal and tumoral) were obtained from the frozen tissue bank of the Human Tissue Network at the Ohio State University.

\section{siRNA transfections}

The Silencer Pre-designed siRNA against human SNF2L (ID\#12578) was obtained (Ambion, Inc.). The target site of siRNA was Exon 2 of SNF2L. The sequences of siRNA oligonucleotide duplex were as follows: 5'-GGAAAUGGACCCAGAAUAUTT-3' (sense) and 5'-AUAUUCUGGGUCCAUUUCCTT-3' (antisense). The siRNA oligonucleotide duplex targeted to SNF2LT (A1IS) was synthesized (Integrated DNA Technologies, Inc., Coralville, IA) and their sequences were as follows: 5'-CAUGAUCUAUGGGUCAGAUUU-3' (sense) and 5'-AUCUGACCCAUAG AUCAUGUU-3' (antisense). The target site of siRNA (ID\#12667) was exon 18 of SNF2LT but exon 19 of SNF2L. Negative control siRNA (ID\#AM4611) (NCSI) was obtained (Ambion, Inc.). Cells were reverse transfected with siRNA (50 nM) using Lipofectamine RNAiMAX Transfection Reagent (Invitrogen Corporation, Inc.).

\section{Plasmid constructions}

Human full-length SNF2L ORF cDNA was synthesized by RT-PCR using the human breast carcinoma cell line MDA-MB-468 cDNA as template. SNF2L cDNA and SNF2LT were separately cloned into vector pCR2.1TOPO (Invitrogen, Inc., Carlsbad, CA) and sequenced. The SNF2LT ORF was subcloned into pcDNA ${ }^{\mathrm{TM}} 6.2$ / Myc-His-A to construct the SNF2LT expression vector pcDNA $^{\mathrm{TM}} 6.2 / \mathrm{SNF} 2 \mathrm{LT}-\mathrm{Myc}-\mathrm{His}$ with the C-terminal myc epitopes and the polyhistidine tags. This vector was transfected directly into cultured cells using Lipofectamine 2000 (Invitrogen, Inc.). (See Supplementary Information on line).

\section{Cell growth, cell cycle and apoptosis experiments}

Cells were transfected with the different siRNAs and seeded in 24-well cell culture plates. The number of viable cells in each well was counted every $24 \mathrm{~h}$ for 3 d using trypan blue exclusion. The cell growth study was carried out in triplicate and repeated at least four times. For cell cycle analysis, the cells were collected 12 to $24 \mathrm{~h}$ after transfection and fixed in $70 \%$ ethanol at $-20^{\circ} \mathrm{C}$, followed by washing once in PBS and staining in PI solution (69 mmol/L PI, $388 \mathrm{nmol} / \mathrm{L}$ sodium citrate, 
$100 \mu \mathrm{g} / \mathrm{mL}$ RNase A) for $15 \mathrm{~min}$ at room temperature. Ten thousand cells were analyzed on Coulter Epics XL flow cytometer (Beckman Coulter, Inc., Brea, CA). For the apoptosis assay, cells were harvested at 48 to $72 \mathrm{~h}$ following transfection. The apoptosis assay used Annexin V-FITC and PI (kit PN IM2375, Beckman Coulter, Inc.) with flow cytometric analysis.

\section{DNA damage and the DNA damage response with apoptosis inhibition}

To determine the order of cellular events with SNF2L, SNF2LT or dual knockdown, selected cell lines, e.g., MDA-MB-468 cells, were seeded in six-well plates and incubated in $37^{\circ} \mathrm{C}$ overnight. Cells were treated first with general caspase inhibitors (Caspase Inhibitor Set IV, EMD Chemicals, Billerica, MA) for $45 \mathrm{~min}$ and then with the different siRNA's for $24 \mathrm{~h}$. Treated cells were collected and divided into three aliquots: the first aliquot was analyzed for apoptosis; the second aliquot was studied for DNA damage by the CometAssay; and a third aliquot was analyzed for protein levels of p-H2XA.

A

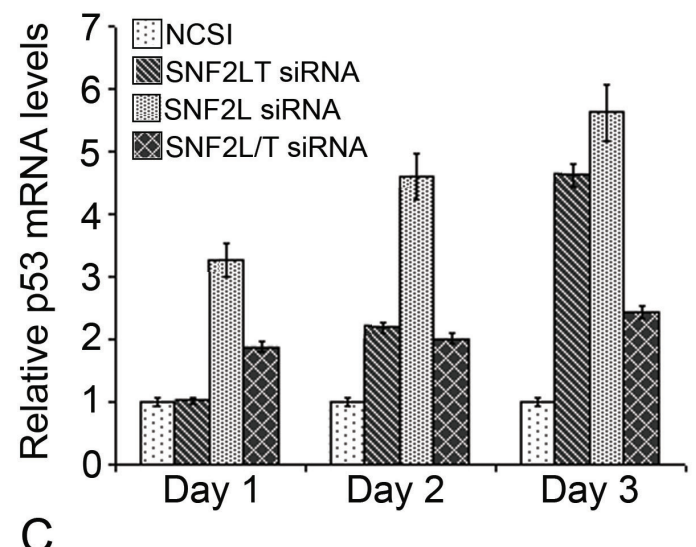

C



\section{Alkaline comet assay}

The CometAssay (single-cell gel electrophoresis assay; Trevigen, Inc., Gaithersburg, MD) was used to evaluate DNA damage. The technique used electrophoresis of lysed cells embedded in an agarose gel, diluted in a SYBR green solution and viewed by DNA fluorescence. Cells with damaged DNA exhibited migration of their DNA outside of the nucleus, producing a comet tail.

\section{RNA isolation and cDNA synthesis}

The total RNA was isolated from cultured cells using RNeasy Mini Kit (Qiagen Inc., Valencia, CA). Total RNA was dissolved in RNase-free water and the concentration determined by measuring absorbance using Nanodrop spectrophotometer at $260 \mathrm{~nm}$. For first strand cDNA synthesis, SuperScript ${ }^{\circledR}$ III First-Strand Synthesis System (Invitrogen, Inc.), ologo (dT)20 and $1 \mu \mathrm{g}$ of total RNA were used. The synthesized cDNA was used for regular RT-PCR or real-time PCR analysis of relative expression levels of target genes.

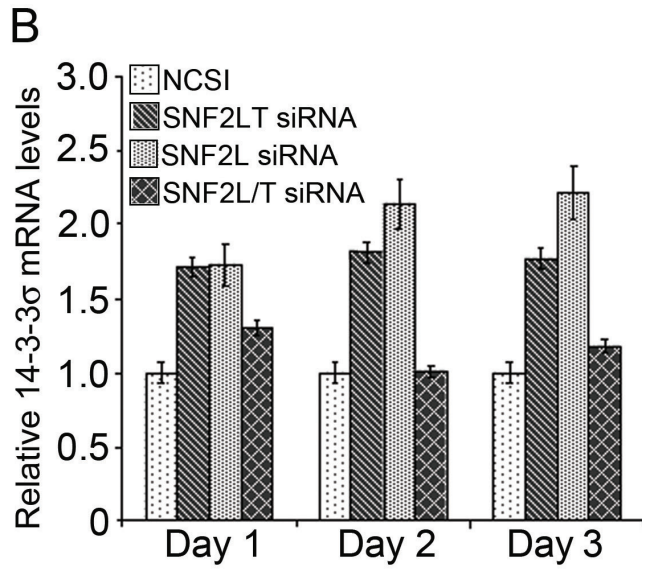

Figure 5: Singular v dual knockdown of SNF2L and SNF2LT and the cell cycle. MDA-MB-468 cells were transfected with the different siRNAs. A, singular knockdowns of either SNF2L or SNF2LT both led to substantial increases in p53 mRNA but dual knockdowns affected p53 mRNA less so by real time RT-PCR. B, singular knockdowns of either SNF2L or SNF2LT both led to substantial


both led to substantial increases in another p53 target gene, GADD45A but dual knockdowns did not affect GADD45A. Each experiment was performed in triplicate and repeated at least four times. 


\section{RT and real-time PCR}

An aliquot of 20 ng cDNA was used in each $25 \mu \mathrm{L}$ PCR reaction, using Platinum Taq DNA Polymerase High fidelity (Invitrogen, Inc.). The following conditions used were as follows: denaturation at $94^{\circ} \mathrm{C}$ for $30 \mathrm{~s}$, annealing at $58^{\circ} \mathrm{C}$ for $30 \mathrm{~s}$, and extension at $68^{\circ} \mathrm{C}$ for $1 \mathrm{~min}$ for a total of 25,30 , or 35 cycles. PCR products were analyzed by $2.0 \%$ agarose gel. Real-time PCR was done on a ABI 7500 Real-time PCR System (Applied Biosystems, Inc., Foster City, CA). cDNA was combined with primer sets and Power SYBR Green PCR Master Mix (Applied Biosystems, Inc.) was used. Gene expression levels were calculated relative to the housekeeping gene $\beta$-actin (ACTB) by using 7500 System SDS software (Applied Biosystems, Inc.). Primer sets (forward and reverse) used for either RT-PCR or real-time PCR included the following (forward, reverse):

\section{Human SNF2L:}

$$
\begin{aligned}
& \text { 5'-ACGGCCTCCAAAACAGCCAAATG-3', } \\
& \text { 5'-TGAGCCAGAGCTGGATTTGGGATA-3' }
\end{aligned}
$$

ATM:

5'-TGGATCCAGCTATTTGGTTTGA-3', 5'-CCAAGTATGTAACCAACAATAGAAGAAGTAG-3'

ATR:

$$
\begin{aligned}
& \text { 5'-TGTCTGTACTCTTCACGGCATGTT-3', } \\
& \text { 5'-AGAGGTCCACATGTCCGTGTT-3' }
\end{aligned}
$$

\section{CHK1:}

5'-GGTGAATATAGTGCTGCTATGTTGACA-3', 5'-TTGGATAAACAGGGAAGTGAACAC-3'

\section{CHK2:}

$$
\text { 5'-AGTGAGAGGACTGGCTGGAGTT-3', }
$$$$
\text { 5'-CCCAAGGCTCCTCCTCACA-3' }
$$

TP53:

$$
\begin{aligned}
& \text { 5'-TCAACAAGATGTTTTGCCAACTG-3', } \\
& \text { 5'-ATGTGCTGTGACTGCTTGTAGATG-3' }
\end{aligned}
$$

14-3-3б:

$$
\begin{aligned}
& \text { 5'-TGCTGCCTCTGATCGTAGGAATTG-3', } \\
& \text { 5'-TTCCCTCAATCTCGGTCTTGCACT-3' }
\end{aligned}
$$

\section{GADD45A:}

5'-TCAGCGCACGATCACTGTC-3', 5'-CCAGCAGGCACAACACCAC-3'

APAF-1:

$$
\begin{aligned}
& \text { 5'-GCATCACCCTTTGTAATAAC-3', } \\
& \text { 5'-CCCAGCTAATTTTTGTAGTT-3' }
\end{aligned}
$$

BAD:

$$
\begin{aligned}
& \text { 5'-TTAAACCTGGCTCGCGACTT- 3 ', } \\
& \text { 5' -GTGCTGTCTCCTTTGGAGGG-3'; }
\end{aligned}
$$

BAX:

5'-CCTTTTCTACTTTGCCAGCAAAC-3', 5'-GAGGCCGTCCCAACCAC-3'

BIK:

$$
\begin{aligned}
& \text { 5'-CTTGATGGAGACCCTCCTGTATG-3', } \\
& \text { 5' -AGGGTCCAGGTCCTCTTCAGA-3' }
\end{aligned}
$$

BAK1:

$$
\begin{aligned}
& \text { 5'-GAACAGGAGGCTGAAGGGGT-3', } \\
& \text { 5' -TCAGGCCATGCTGGTAGACG-3' }
\end{aligned}
$$

BID:

$$
\begin{aligned}
& \text { 5'-GGTCTTACAGCAGGCAGTATCC-3', } \\
& \text { 5'-TCAGAATCTCTGTGCCATGTG-3' }
\end{aligned}
$$

BCL2:

5'-GGAACAATGCAGCAGCCGAG-3', 5'-GTAGAGTGGATGGTCAGTGT-3'

CASP1:

5'AATACTGTCAAATTCTTCATTGCAGATAA-3', 5'-AAGTCGGCAGAGATTTATCCAATAA-3'

CASP3: 5'-AGAACTGGACTGTGGCATTGAG-3',
5'-GCTTGTCGGCATACTGTTTCAG-3'

CASP6:

5'-ACCTCCCACACTGGGAACCACA-3', 5'-CACCTGTATGACCAATTCCATGTC-3'

CASP7:

5'-AGTGACAGGTATGGGCGTTCG-3',

5'-GCATCTATCCCCCCTAAAGTGG-3'

CASP8:

5'-CCTGGGTGCGTCCACTTT-3', 5'-CAAGGTTCAAGTGACCAACTCAAG- 3'

CASP9:

5'-ATAACCTTTTAGGCTGGTGG-3', 5'-AGAGCAGAAAGAGGTGAGAGA-3'

CASP10:

5'-CCCTTAAACATTGGACAGTG-3', 5' -GTGTAAATGAGCCATCATCTTC-3'

ACTB:

5'-GGCACCCAGCACAATGAAG-3', 5'-GCCGATCCACACGGAGTACT-3'

\section{Preparation of protein lysates and western blot analysis}

To prepare protein lysates from cultured cell lines for western blot analysis, cells were lysed using ice-cold RIPA lysis buffer $(50 \mathrm{mM}$ Tris, $150 \mathrm{mM} \mathrm{NaCl}, 50 \mathrm{mM}$ 
$\mathrm{NaF}, 1 \mathrm{mM} \mathrm{Na} 4 \mathrm{P} 2 \mathrm{O} 7 \cdot 10 \mathrm{H} 2 \mathrm{O}, 0.1 \%$ DOC, 1.0\% NP40, $50 \mu \mathrm{Na}$ NO4, and Halt Protease Inhibitor Cocktail) (Pierce Biotechnology, Inc, Rockford, IL)). After 15 min on ice with shaking, the lysates were centrifuged at 15000 $\times \mathrm{g}$ for $10 \mathrm{~min}$ at $4^{\circ} \mathrm{C}$. Supernatants were stored at $-80^{\circ} \mathrm{C}$ until use. For western blot analysis, protein concentrations were determined using the BCA Protein Assay (Pierce Biotechnology, Inc). Equal amounts of boiled protein were loaded onto a 4-12\% Precast gradient gel (Invitrogen, Inc.) and transferred to nitrocellular membranes. The membranes were washed in TBST buffer. Membranes were then washed and incubated with secondary antibody for 1 hour at room temperature. Bound antibodies were detected by a chemiluminescent detection system (West Femto; Pierce Biotechnology, Inc.).

\section{Other studies}

Additional studies of constitutive and conditional gene expression of SNF2L and SNF2LT were carried out with transient and stable transfection methods. (See Supplementary Information on line).

\section{Institutional approvals and human tissues}

Use of human tissues was approved by The Ohio State University Cancer Institutional Review Board under protocol 2006C0042. Specifically, select normal and cancerous tissues were obtained from an anonymized frozen tissue bank. All animal and in vitro studies were approved by The Ohio State University's Animal Care and Use Committee (Institutional Animal Care and Use Committee), protocol 2007A0218, and by the Institutional Biosafety Committee, protocol 2007R0057. Additional animal studies were approved by the University of Nevada, Reno's Institutional Animal Care and Use Committee, protocols 00439 and 00440.

\section{Statistical analysis}

All experiments performed were subjected to statistical analyses. Each experiment was performed in triplicate and repeated at least four times. Representative results were depicted. Declarations of differences imply differences of statistical significance. Significance was assessed by the Student's t-test.

\section{RESULTS}

\section{Serendipitous discovery of human SNF2LT (A1IS), a novel truncated isoform of human SNF2L}

In initially studying SNF2L expression, it was noted that the expression levels of SNF2L were highest in ovary and testis [21]. The exon-intron map of SNF2L is depicted (Figure 1A). RNA from ovary was subjected to RT-PCR with primers which annealed to exon 17 located at 2097-2120 nt of SNF2L (primer A1EX17FW) and exon 19 at 2367-2384 nt (primer A1EX19RE) (Figure 1B). The amplified products were separated on a $1.5 \%$ agarose gel and stained with ethidium bromide (data not shown). As expected, one amplification product of approximately 300 bp was observed as the SNF2L cDNA product. Interestingly, we found another amplification product about $550 \mathrm{bp}$ in length. This 550-bp product was excised from the gel and purified and sequenced. Nucleotide sequencing revealed that the 5'end and the 3 'end of the 550-bp product were the sequences of SNF2L cDNA. However, the central $250 \mathrm{bp}$ fragment of this product did not match the sequence of SNF2L cDNA. We performed a blast analysis using the $250 \mathrm{bp}$ fragment sequence on the NCBI website and discovered that this $250 \mathrm{bp}$ fragment was the whole sequence of intron 18 of the SNF2L gene. This raised the possibility that we might have stumbled on a novel alternatively spliced isoform of SNF2L. To further confirm the new alternatively spliced mRNA containing intron 18 of SNF2L, we used two pairs of primers for RT-PCR that covered intron 18 (Figure 1B). The primer SNF2LFW (A1FW) which annealed to the 5'end of SNF2L cDNA and SNF2LTRE (A1ISRE) which annealed to the 3'end of intron 18 were used to amplify the sequence that covered the 5 'end of SNF2L and a significant portion of intron 18. The primer SNF2LTFW(A1ISFW) which annealed to the 5'end of intron 18 and SNF2LRE(A1RE) which annealed to the 3 'end of SNF2L cDNA were used to amplify the sequence that covered the 3 'end of SNF2L and a significant portion of intron 18. The amplified products were again separated on a $1.5 \%$ agarose gel and stained with ethidium bromide. As expected, two amplification products were observed: one approximately 2500-bp from primers SNF2LFW(A1FW) and SNF2LTRE(A1ISRE) and one about 1800-bp from primers SNF2LTFW(A1ISFW) and SNF2LRE(A1RE) (data not shown). The products were again excised from the gel and purified and sequenced. The nucleotide sequence confirmed that the full-length cDNA was a novel alternatively spliced mRNA isoform (named as SNF2LT(A1IS)) that contained full length intron 18 (Figure 1B). Blast analysis of SNF2LT(A1IS) revealed that this isoform had not been previously reported. As 
schematically shown (Figure 1B), SNF2LT mRNA is 4310 nucleotides in length compared to 4102 nucleotides of SNF2L mRNA. Intron 18 of the SNF2L gene is not spliced out but exists in SNF2LT mRNA as an exon sequence. Because a stop codon is introduced in intron 18, SNF2LT encodes only a 776 amino acid protein that lacks the 262 amino acid C-terminal of SNF2L (Figure 1C; Figure 1D). SNF2LT also lacks 12 amino acids that correspond to amino acids 543-554 of the full length SNF2L protein (Figure 1D). Compared to the full length SNF2L protein, SNF2LT lacks three important domains: HAND, SANT and SLIDE (Figure 1C). We reported SNF2LT to GenBank (bankit1082498 EU36009).

\section{Nearly ubiquitous expression of SNF2LT in both normal and cancerous human tissues and their derived cell lines}

Our previous results showed that human SNF2L was expressed nearly ubiquitously in both normal and human cancerous tissues and their derived cell lines [21]. Human SNF2LT was also expressed nearly ubiquitously in diverse normal (Figure 2A) and human cancerous tissues (Figure 2B) and their derived cell lines (Figure 2C) which included highly malignant (HM), low grade (LG) or

A

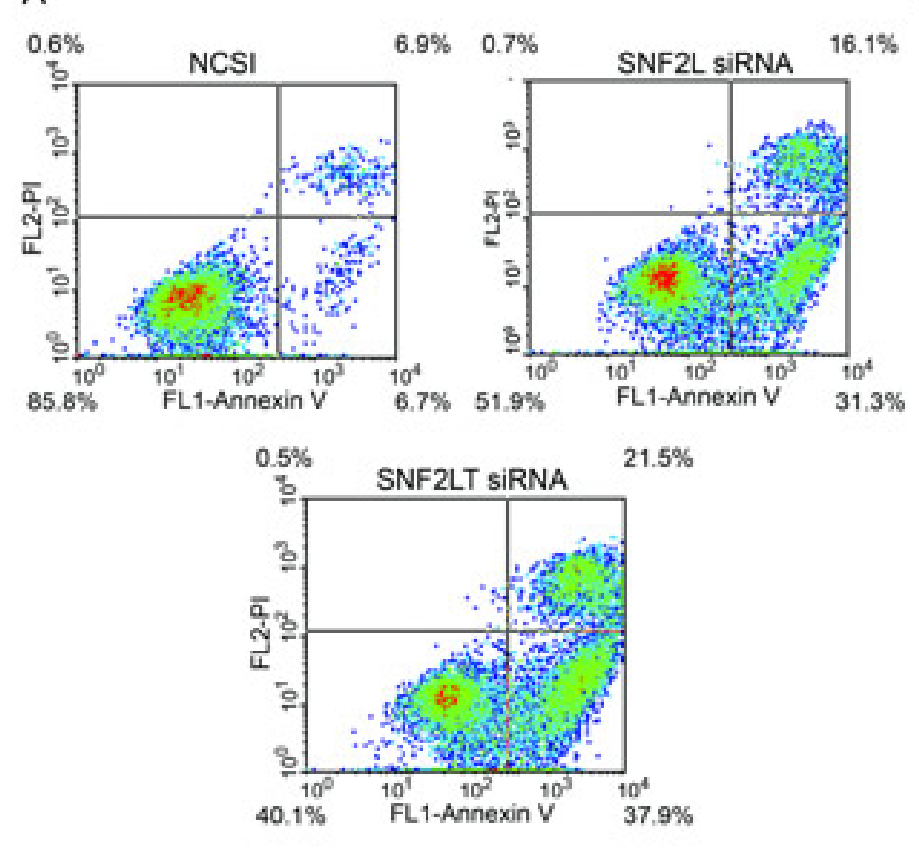

benign and normal untransformed (NU) human cell lines. Compared to SNF2L mRNA, the level of SNF2LT mRNA was usually lower than the level of SNF2L, averaging about $50 \%-75 \%$ lower on a molar basis (Figure 2A; Figure 2B; Figure 2C). The expression of SNF2LT also paralleled the expression of SNF2L: when the expression of SNF2L was high, as it was in the majority of HM lines examined, the expression of SNF2LT was also high; when SNF2L expression was low, so was the expression of SNF2LT. Interestingly the expression of SNF2L as well as its SNF2L isoform were low to absent in MARY-X, a transplantable human xenograft derived from a case of inflammatory breast cancer [26]. In both MARY-X and its in vitro derived spheroids thought equivalent to in vivo lymphovascular emboli, the expression of both SNF2L as well as SNF2LT remained low to absent. Although SNF2L was detected in murine tissues in a prior study [21], using equivalent primers, murine SNF2LT could not be detected (data not shown). Therefore it appeared as if SNF2LT might be a human specific isoform.

\section{Singular v dual knockdowns of SNF2L/SNF2LT}

Singular v dual SNF2L and SNF2LT knockdowns could be achieved with targeted siRNA oligonucleotide duplexes (Figure 3A): the Silencer Pre-designed siRNA

B

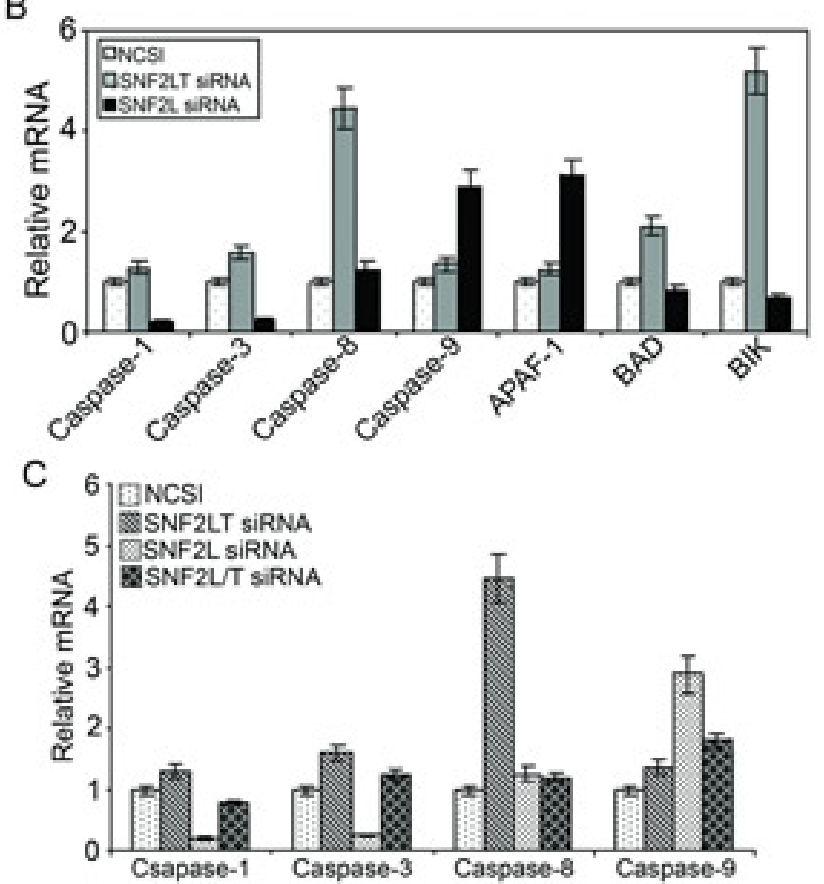

Figure 6: Singular v dual knockdown of SNF2L and SNF2LT and apoptosis. MDA-MB-468 cells were transfected with the different siRNAs. A, MDA-MB-468 cells were monitored over the next 48-72 hours with Annexin V-FITC and propidium iodide (PI) staining. The percentage of total apoptotic cells (early and late apoptosis) is depicted. Singular knockdowns of either SNF2L or SNF2LT both led to substantial increases in both early as well as late apoptosis. Dual knockdowns did not result in apoptosis over levels induced by the NCSI negative control (data not shown). During this time period the relative mRNA levels of potential genes involved in the apoptotic process was surveyed. B, singular knockdown of SNF2L led to a significant increase in Apaf-1 and caspase 9 whereas singular knockdown of SNF2LT led to a significant increase in caspase 8, BAD and BIK. C, dual knockdowns compared to NCSI knockdown did not result in a significant increase in any caspase. Each experiment was performed in triplicate and repeated at least four times. 
against human SNF2L (ID\#12578) targeted against Exon 2 of SNF2L; the siRNA oligonucleotide duplex targeted to SNF2LT (A1IS); and the siRNA (ID\#12667) against exon 18 of SNF2LT and exon 19 of SNF2L. siRNA (NCSI) was used as a negative oligonucleotide duplex control. These specific oligonucleotide duplexes achieved specific singular knockdowns of either SNF2L (RNAi12578) or SNF2LT (RNAi-A1IS) or dual knockdowns of both molecules (RNAi-12667) (Figure 3B). These results could be achieved in the diverse HM, LG or NU human cell lines which were examined. The specific knockdowns that were achieved were only partially predictable. A1IS siRNA targeted to "intron 18" that exists as an exon in A1IS mRNA but as an intron in SNF2L mRNA predictably knocked down SNF2LT (A1IS) but not SNF2L. 12578 siRNA targeted to the 5' part of both SNF2L and A1IS mRNA and 12667 siRNA targeted to exon 18 of A1IS mRNA but exon 19 of SNF2L. Both 12578 and 12667 siRNAs might well be expected to separately knockdown both SNF2L as well as SNF2LT. However, 12578 siRNA selectively inhibited expression of SNF2L and had little effect on the expression of A1IS (Figure 3B). The molecular reasons for this selective knockdown were not clear. 12667 siRNA predictably led to the knockdowns of both SNF2L and A1IS (Figure 3B) and could be exploited to achieve dual knockdowns.

\section{Singular $v$ dual knockdowns of SNF2L/SNF2LT and opposite effects on cell growth}

After demonstrating that specific singular and dual knockdowns of full length SNF2L and its truncated isoform, SNF2LT could be achieved, we next examined the effects of these knockdowns on cell growth of a number of different cell lines including HM, LG and NU lines (complete list of lines examined provided in Materials and Methods). Our results showed that the growth of all the HM lines examined were dramatically inhibited when singular knockdowns of either SNF2L or SNF2LT were achieved (Figure 3C). In the HM lines, eg., MDA-MB-468 and MDA-MB-231, not only was there growth inhibition but the cell numbers were reduced by day 3 below starting numbers indicating that, in addition to the growth arrest, that induction of cell death or apoptosis had occurred. When one looks closely at the cell numbers, one finds that the growth of the cells subjected to SNF2LT knockdown was even more reduced than the growth of the same cells subjected to SNF2L knockdown (Figure 3C). In contrast, the LG and NU lines showed substantially less growth inhibition with no reduction in cell numbers. The growth rate of the HM lines were essentially the same when transfected with the negative control siRNA (Figure 3C). Dual knockdowns of SNF2L and SNF2LT, however, exhibited an increase in cell growth, findings dramatically opposite to the effects of singular knockdown (Figure 3C).

\section{Singular v dual knockdowns of SNF2L/SNF2LT and similar effects on DNA damage}

In a recent study [21], we found that HM cell lines, although expressing SNF2L at similar levels as their normal counterparts, were exquisitely sensitive to its knockdown. Only HM lines showed significant growth inhibition, DNA damage, a DNA damage response, and phosphorylation of checkpoint proteins and marked apoptosis. In that study we believed that SNF2L knockdown triggered DNA damage which then resulted in a DNA damage response which caused a cell cycle growth arrest and the induction of apoptosis. In the present study, we wanted to compare the effects of singular knockdown of SNF2LT with singular knockdown of SNF2L on DNA damage. We also wanted to compare the effects of dual knockdowns with singular knockdowns. Singular knockdown of SNF2LT similarly triggered DNA damage as did singular knockdown of SNF2L as measured by the Comet assay (Figure 4A). This was observed in all $\mathrm{HM}$ lines examined. H2AX is a surrogate marker of DNA damage. DNA damage results in an immediate phosphorylation of the histone $\mathrm{H} 2 \mathrm{~A}$ family member $\mathrm{H} 2 \mathrm{AX}$ at Ser139. Ser139-phosphorylated H2AX localizes to sites of DNA damage at subnuclear foci. We examined the level of phosphorylated H2AX (p-H2AX) by Western blotting and found that $\mathrm{p}-\mathrm{H} 2 \mathrm{AX}$ was significantly increased with the singular knockdowns of either SNF2L or SNF2LT in all HM lines examined (Figure 4B). Dual knockdowns of both SNF2L and SNF2LT similarly led to DNA damage determined by both the Comet assay as well as by an increase in p-H2AX (data not shown).

\section{Singular $v$ dual knockdowns of SNF2L/SNF2LT and opposite effects on the DNA damage response and the cell cycle}

DNA damage is thought to activate a DNA damage response, in which the center is the ATM/ATR kinase signaling pathway. ATM/ATR kinases phosphorylate the downstream effectors such as p53, Chk1, Chk2 and BRCA1. To this end, we investigated whether the critical DNA damage response network is activated by DNA damage when the DNA damage is triggered by singular $\mathrm{v}$ dual knockdowns of SNF2L and SNF2LT. We examined this DNA damage response in a number of different HM lines including MDA-MB-468, MDA-MB-231 and HeLa. We used western blotting to examine the levels of phosphorylated proteins of ATM, ATR, BRACA1, Chk1 and Chk2. Neither singular nor dual knockdowns of SNF2L and SNF2LT resulted in an increase in phosphorylated ATM. Singular knockdowns of SNF2L and SNF2LT however resulted in increased phosphorylations of ATR, CHK1, CHK2 but no alterations of their respective total proteins (data not shown). Interestingly 
while the singular knockdown of SNF2L led to an increase in phosphorylated BRCA1 [21], the singular knockdown of SNF2LT did not do so. However dual knockdowns of both SNF2L and SNF2LT did not result in increased phosphorylations of ATR, BRCA1, CHK1, CHK2 (data not shown). Therefore dual knockdowns did not result in a typical DNA damage response.

Singular $\mathrm{V}$ dual knockdowns of SNF2L and SNF2LT had different effects on the triggering of cell cycle checkpoints. Singular knockdowns of SNF2L and SNF2LT resulted in nearly identical increases in relative levels of p53 mRNA (Figure 5A), 14-3-3 $\sigma$ (Figure 5B) and GADD45A (Figure 5C). However dual knockdowns of SNF2L and SNF2LT resulted in no appreciable alterations in these critical cell cycle checkpoint proteins (Figure 5A; Figure 5B; Figure 5C). Singular knockdowns of SNF2L and SNF2LT also resulted in an increase in phosphorylation of p53 but dual knockdowns did not alter phosphorylation of p53 (data not shown). Since the cellular responses to DNA damage, such as cell cycle arrest, DNA repair, chromatin remodeling, and apoptosis are all thought to be well coordinated, we investigated whether singular $\mathrm{v}$ dual knockdowns of SNF2L and SNF2LT led to alterations in the cell cycle. Our results indicated that the HM lines examined exhibited a mild G2/M arrest with either singular SNF2L or SNF2LT knockdown. Dual knockdown did not result in a cell cycle arrest. In fact dual knockdowns resulted in an increase in proliferation (Figure 3C). Our results also showed that with singular knockdowns, the level of phosphorylated $\mathrm{cdc} 2$ was increased but not the level of phosphorylated $\mathrm{Rb}$ (Ser795) (data not shown). Since the cdc2/cyclin B kinase is thought to be pivotal in regulating the G2/M transition and $\mathrm{Rb}$ thought to control progression through late $\mathrm{G} 1 / \mathrm{S}$, our findings indicated that the effects of either SNF2L or SNF2LT inhibition on the cell cycle were largely directed at checkpoints that regulate $\mathrm{G} 2 / \mathrm{M}$, a finding confirmed by the mild G2/M arrest noted on flow cytometric analysis. Our observations regarding the critical targets of p53: GADD45 and 14-3-3 $\sigma$ also being increased in either singular SNF2L or SNF2LT knockdown but not dual knockdown again emphasize the fundamental differences between singular v dual knockdown with regard to effects on the cell cycle. Since GADD45A and 14-3-3 $\sigma$ both target the cyclin $\mathrm{B} / \operatorname{cdc} 2$ complex, this would appear as further confirmatory evidence that $\mathrm{G} 2 / \mathrm{M}$ is targeted with either singular knockdown but not dual knockdown.

\section{Singular v dual knockdowns of SNF2L/ SNF2LT and opposite effects on apoptosis}

Staining with FITC-conjugated annexin $\mathrm{V}$ and propidium iodide (PI) was used to identify subpopulations of cells with apoptosis. With singular knockdowns of either SNF2L and SNF2LT using MDA-MB-468 cells, a significant and near equivalent degree of apoptosis was induced (Figure 6A). Dual knockdowns did not result in apoptosis over levels induced by the NCSI negative control. We applied real-time PCR to detect which apoptotic pathway was activated when either SNF2L or SNF2LT was knocked down. Although either singular knockdown resulted in the near equivalence in the degree of apoptosis, different apoptotic pathways appeared involved. With SNF2L knockdown (Figure 6B), increased Apaf-1 and increased caspase-9 expression was observed. With SNF2LT knockdown, we found instead that caspase $8, \mathrm{BAD}$ and BIK increased (Figure 6B). Therefore, the apoptotic pathway triggered by SNF2LT knockdown appeared different from the apoptotic pathway caused by SNF2L knockdown. Dual knockdowns did not appreciably activate any caspase pathway and were nearly identical to NCSI knockdown (Figure 6C). Schematic summarizes our findings (See Supplementary Information on line).

\section{SNF2LT overexpression and apoptosis}

Based on our prior experiments we reasoned that since SNF2L knockdown inhibited cell growth, that SNF2L overexpression might be expected to enhance cell growth. To investigate whether the expression of SNF2LT would promote cell growth, we constructed an expression vector that overexpressed SNF2LT both constitutively and conditionally. We examined the effects of SNF2LT overexpression by both transient as well as stable transfections. Surprisingly we did not observe an increase in cell growth but rather an inhibition of cell growth and an induction of apoptosis. From this we reasoned that it was the ratio of SNF2LT to SNF2L that determined cell proliferation $\mathrm{v}$ apoptosis and that the singular overexpression of either full length SNF2L or its truncated isoform, SNF2LT was the ratio equivalence of singular knockdowns with the result being cell cycle arrest and cell death (See Supplementary Information on line).

\section{DISCUSSION}

Epigenetic changes in gene expression play important roles in the development, progression and ultimate therapeutic targeting of human cancers [29-31]. In addition to the major mechanisms of DNA methylation and histone modification thought to regulate epigenetic changes $[2,3,32,33]$, altered nucleosome positioning through chromatin-remodeling complexes are playing increasingly prominent roles in this area $[4,5,11,12,13]$. Loss of SNF2L complex activity could represent a novel mechanism for altering gene expression during tumor progression. Similarly other types of SNF2L complex alterations could prove deleterious to cancer cells. The SNF2L complex itself could therefore be a potential therapeutic target. 
In studying SNF2L, we discovered a novel truncated isoform, SNF2LT which formed the basis of the present study. When compared to full length SNF2L, SNF2LT lacked three important domains: HAND, SANT and SLIDE. Truncated isoforms usually have antagonistic effects, eg., dominant negative effects, on their full length molecule. Here SNF2LT seemed synergistic. However, we compared the effects of SNF2LT knockdown with the effects of SNF2L knockdown and although there were some minor differences in the changes effected by SNF2L v SNFLT knockdown on select cell cycle proteins, eg. p-BRCA1 and apoptosis pathways triggered, eg. caspase $9 \mathrm{v}$ caspase 8 , there was much more in common between singular SNF2L v singular SNF2LT knockdown in inducing DNA damage, a DNA damage response, cell cycle arrest and apoptosis selectively in cancer cell lines. Therefore SNF2LT's effects on SNF2L certainly were not of a dominant negative nature. The effects of dual knockdowns of SNF2L and SNF2LT were very different than their singular knockdowns. Dual knockdown induced DNA damage but did not result in a DNA damage response, a cell cycle arrest or apoptosis. In fact cancer cell lines subjected to dual knockdown paradoxically exhibited increased cell growth. Our findings indicated that SNF2L and its isoform tightly regulate the cancer cell's response to DNA damage. Cancer cell lines which endogenously express low levels of both SNF2L and its isoform would mimic the situation of dual knockdown and would experience DNA damage allowed to propagate unchecked.

SNF2LT is not the only alternatively spliced isoform of SNF2L to have been described but it is perhaps the most important isoform because of its near ubiquity of expression, the similar functional consequences of its singular knockdown compared with SNF2L knockdown and its presumed interactions (direct or indirect) with the full length molecule. A number of other alternatively spliced variants of SNF2L expressed in multiple cell types and exhibiting different subcellular localizations and functions have been described [34,35]. These specific isoforms were generated through the alternate use of exons 1 and 13 , and by the use of alternate donor splice sites within exon 24. Alternate splicing within exon 24 removed a NLS sequence and altered the subcellular distribution of the SNF2L protein $[34,35]$. Still another splice variant of human SNF2L called SNF2L +13 which contained a nonconserved in-frame exon within the conserved catalytic core domain of SNF2L has been described [22]. This latter variant of SNF2L, SNF2L +13 , retained its ability to incorporate into multiprotein complexes but was devoid of enzymatic activity. This SNF2L + 13 splice variant was predominately found in nonneuronal cells of the nervous system. None of these other splice variants exhibited the near ubiquity of expression of SNF2LT. None of these other splice variants have been demonstrated to have effects on DNA damage, the DNA damage response and the cell cycle. None of these other splice variants have been shown to interact directly or indirectly with full length SNF2L.

Both the relative as well as the absolute amounts of SNF2L and its isoform SNF2LT are obviously critical to their functions. When the relative amounts (their ratios) were altered through knockdown or overexpression, HM lines responded by DNA damage, a DNA damage response, cell cycle arrest and apoptosis. When the absolute amounts were altered through either dual knockdown or, presumably, in the natural situation of endogenously low levels of expression of both SNF2L as well as SNF2LT, such as occurs in MARY-X and its derived spheroids, the response would be different: DNA damage but no DNA damage response, no cell cycle arrest and no apoptosis. In MARY-X lymphovascular emboli and its in vitro derived spheroids thought to be equivalent to each other [36], DNA damage would be allowed to propagate unchecked.

The singular effects of SNF2LT and SNF2L knockdown on DNA damage, the DNA damage response, the cell cycle and apoptosis, while strikingly similar, did exhibit some differences. For example, while the singular knockdown of SNF2L led to an increase in p-BRCA1 [21], the singular knockdown of SNF2LT did not do so. The latter results suggested that the knockdown of SNF2LT might selectively block the DNA repair pathway involving p-BRCA1. This could explain why the growth of the cells subjected to SNF2LT knockdown were even more reduced than the growth of the same cells subjected to SNF2L knockdown. Another example of differences between SNF2L and SNF2LT knockdown was not in the triggering of apoptosis but rather in the pathway of apoptosis which was triggered [37-38]. With SNF2L knockdown, Apaf1 was activated which, in turn, activated caspase- 9 and the rest of the caspase cascade including caspase-3. With SNF2LT knockdown, caspase-9 was not activated. Instead, caspase-8, BAD and BIK were activated. BAD is a proapoptotic member of the Bcl-2 family that promotes cell death by displacing BAX from binding to $\mathrm{Bcl}-2$ and Bcl-xL. BIK/Nbk (Bcl-2-interacting killer/natural born killer) is a potent pro-apoptotic protein belonging to a group of the Bcl-2 family. Functionally, BIK is able to bind to and antagonize anti-apoptotic Bcl-2 family members including Bcl-2 and Bcl-xL. The apoptotic pathway triggered by SNF2LT knockdown therefore differed from that triggered by SNF2L knockdown.

Despite the differences between SNF2LT and SNF2L knockdown with respect to certain aspects of the DNA damage response, ie., p-BRCA1 and the differing pathways of apoptosis, singular SNF2LT and SNF2L knockdowns had much more in common and this common response involved alterations in both the levels of p53 as well as its degree of phosphorylation. This common p53 response to either SNF2LT or SNF2L knockdown, in turn, suggests two possible mechanisms: 


\section{Mechanism \#1}

The inhibition of expression of SNF2LT or SNF2L leads to functional losses of SNF2LT or SNF2L or the complexes containing them which then directly causes DNA damage, which, in turn, activates the DNA damage response. In this DNA damage response, p53 is activated through phosphorylation on Ser15 by ATM/ATR and on Ser20 by Chk1/Chk2. p53 plays a very important role in responding to DNA damage and promoting/maintaining checkpoint arrest [39]. For example, phosphorylated p53 activates its key transcriptional targets, GADD45A and $14-3-3 \sigma$ [40]. GADD45A causes the dissociation of the Cdc2 and cyclin complex and 14-3-3 $\sigma$ sequesters the cyclinB/Cdc2 complex in the cytoplasm.

\section{Mechanism \#2}

The inhibition of expression of SNF2LT or SNF2L directly activates the expression of p53. Either mechanism may be occurring singly or in combination with either SNF2LT or SNF2L knockdown.

SNF2LT is a novel alternatively spliced truncated isoform of human SNF2L that lacks the three C-terminal structural domains: HAND, SANT and SLIDE. These three domains are tightly connected and move as one unit during the remodeling process. SANT domains of other proteins, in particular, have been shown to bind histone tails and the histone $\mathrm{H} 4$ tail is important for ISWIdriven nucleosome remodeling [41]. Deletion of the H4 tail or grafting the tail onto another histone abolishes ISWI ATPase stimulation and nucleosome sliding [18]. This means that SNF2LT loses some very important functions: binding to and moving along DNA during the remodeling process and binding to histone, in which the binding may be important for nucleosome remodeling. And yet, SNF2LT knockdown is the near equivalent of SNF2L knockdown. How can these observations be reconciled? Obviously it is important to understand all of the interactions between SNF2L and its truncated isoform, SNF2LT in order to reconcile these observations. SNF2L and SNF2LT may bind each other and form a complex with BPTF and RbAp46/RbAp48. In this complex, SNF2LT may modulate the function of SNF2L and vice versa, adding an additional layer of fine-tuned specificity in ATP-dependent chromatin remodeling. Certainly the similarities in DNA damage, the DNA damage response, cell cycle arrest and apoptosis with either type of singular knockdown suggest that SNF2L does not directly interact with SNF2LT in a dominant negative manner. But SNF2LT may directly interact with SNF2L in a different manner in forming the complex with BPTF and RbAp46/ RbAp48 mentioned above. Co-immunoprecipitation experiments of endogenous substrates which bind SNF2L and/or its isoform would further support or refute such direct interactions.

The disparate effects of SNF2LT/SNF2L dual $v$ singular knockdowns, on the other hand, raise the distinct possibility of a type of indirect interaction between SNF2LT and SNF2L. To further support this type of indirect interaction, one approach would be to analyze expression profiles following SNF2L knockdown, SNF2LT knockdown and dual knockdown determining their degree of overlap. Experiments are presently in progress to determine whether the interactions of SNF2L with its truncated isoform, SNF2LT are direct or indirect or both.

The existence of a functional splice variant of SNF2L, SNF2LT that acts in cohort with SNF2L suggests an additional level of complexity possibly related to their biology. There are many examples in nature where master orchestration of diverse biological functions such as immune homeostasis, innate immunity and global gene expression involve regulation by splice isoform variants. Such examples include FOXP3 and exon 2 deleted FOXP3 $\triangle 2$ [42], the toll-like receptor (TLR) and its alternatively spliced variants [43] and, in this case, SNF2L and its truncated isoform, SNF2LT. In all these examples, it seems as if the greater the master orchestration, the greater is the level of regulatory complexity.

\section{Disclosure of Potential Conflicts of Interest}

No potential conflicts of interest were disclosed.

\section{ACKNOWLEDGMENTS}

We thank Dr. John J. Hasenau, Dr. Walter F. Mandeville, Patricia L. Atkins and Jared H. Smith of Laboratory Animal Medicine for their veterinarian and technical assistance with the maintenance of the MARY-X xenografts.

\section{GRANT SUPPORT}

This study was supported by the Department of Defense Breast Cancer Research Program Grants BC990959, BC024258, BC053405, the American AirlinesSusan G Komen for the Cure Promise Grant KG08128702 and the University of Nevada Vasco A. Salvadorini Endowment.

\section{REFERENCES}

1. Jones PA, Baylin SB: The epigenomics of cancer. Cell 2007, 128:683-692

2. Nan $\mathrm{X}, \mathrm{Ng} \mathrm{HH}$, Johnson CA, Laherty CD, Turner BM, Eisenman RN, Bird A: Transcriptional repression by the methyl-CpG-binding protein $\mathrm{MeCP} 2$ involves a histone deacetylase complex. Nature 1998, 393:386-389

3. Jones PL, Veenstra GJ, Wade PA, Vermaak D, Kass SU, Landsberger N, Strouboulis J, Wolffe AP: Methylated 
DNA and MeCP2 recruit histone deacetylase to repress transcription. Nat Genet 1998, 19:187-191

4. Zhang Y, Ng HH, Erdjument-Bromage H, Tempst P, Bird A, Reinberg, D. Analysis of the NuRD subunits reveals a histone deacetylase core complex and a connection with DNA methylation. Genes Dev 1999, 13:1924-1935

5. Harikrishnan KN, Chow MZ, Baker EK, Pal S, Bassal S, Brasacchio D, Wang L, Craig JM, Jones PL, Sif S, ElOsta A: Brahma links the SWI/SNF chromatin-remodeling complex with MeCP2-dependent transcriptional silencing. Nat Genet 2005, 37:254-264

6. Downs JA, Allard S, Jobin-Robitaille O, Javaheri A, Auger A, Bouchard N, Kron SJ, Jackson SP, Cote J: Binding of chromatin-modifying activities to phosphorylated histone H2A at DNA damage sites. Mol Cell 2004, 16:979-990

7. Morrison AJ, Shen X: DNA repair in the context of chromatin. Cell Cycle 2005, 4:568-571

8. Morrison AJ, Highland J, Krogan NJ, Arbel-Eden A, Greenblatt JF, Haber JE, Shen X: INO80 and g-H2AX interaction links ATP-dependent chromatin remodeling to DNA damage repair. Cell 2004, 119:767-775

9. van Attikum H, Fritsch O, Hohn B, Gasser SM: Recruitment of the INO80 complex by H2A phosphorylation links ATPdependent chromatin remodeling with DNA double-strand break repair. Cell 2004, 119:777-788

10. Wong LY, Recht J, Laurent BC: Chromatin remodeling and repair of DNA double-strand breaks. J Mol Histol 2006, 37:261-269

11. Li H, Ilin S, Wang W, Duncan EM, Wysocka J, Allis CD, Patel DJ: Molecular basis for site-specific read-out of histone H3K4me3 by the BPTF PHD finger of NURF. Nature 2006, 442:91-95

12. Groth A, Rocha W, Verreault A, Almouzni G: Chromatin challenges during DNA replication and repair. Cell 2007, 128:721-733

13. Eisen JA, Sweder KS, Hanawalt PC: Evolution of the SNF2 family of proteins: subfamilies with distinct sequences and functions. Nucleic Acids Res 1995, 23: 2715-2723

14. Chai J, Charboneau AL, Betz BL, Weissman BE: Loss of the hSNF5 gene concomitantly inactivates p21CIP/ WAF1 and p16INK4a activity associated with replicative senescence in A204 rhabdoid tumor cells. Cancer Res 2005, 65: 10192-10198

15. Roberts CW, Orkin SH: The SWI/SNF complex-chromatin and cancer. Nat Rev Cancer 2004, 4:133-142

16. Eberharter A, Vetter I, Ferreira R, Becker PB: ACF1 improves the effectiveness of nucleosome mobilization by ISWI through PHD-histone contacts. EMBO J 2004, 23:4029-4039

17. Wang GG, Allis D, Chi P: Chromatin remodeling and cancer, part II: ATP-dependent chromatin remodeling. Trends in Molecular Medicine 2007, 13: 373-380

18. Bouazoune $\mathrm{K}$, Brehm A: ATP-dependent chromatin remodeling complexes in Drosophila. Chromosome
Research 2006, 14:433-449

19. Tsukiyama T, Wu C: ISWI, a member of the SWI2/ SNF2 ATPase family, encodes the $140 \mathrm{kDa}$ subunit of the nucleosome remodeling factor. Cell 1995, 83: 1011-1020

20. Tsukiyama T, Daniel C, Tamkun J, Wu C: Purification and properties of an ATP-dependent nucleosome remodeling factor. Cell 1995, 83:1021-1026

21. Ye Y, Xiao Y, Wang W, Wang Q, Yearsley K, Wani AA, Yan Q, Gao JX, Shetuni BS, Barsky SH: Inhibition of expression of the chromatin remodeling gene, SNF2L selectively leads to DNA damage, growth inhibition and cancer cell death. Mol Cancer Res 2009, 7:1984-1999

22. Barak O, Lazzaro MA, Cooch NS, Picketts DJ, Shiekhattar R: A tissue-specific, naturally occurring human SNF2L variant inactivates chromatin remodeling. J Biol Chem 2004, 279:45130-45138

23. Pepin D, Vanderhyden BC, Picketts DJ, Murphy BD: ISWI chromatin remodeling in ovarian somatic and germ cells: revenge of the NURFs. Trends Endocrinol Metab 2007, $18: 215-224$

24. Wysocka J, Swigut T, Xiao H, Milne TA, Kwon SY, Landry J, Kauer M, Tackett AJ, Chait BT, Badenhorst P, $\mathrm{Wu}$ C, Allis CD: A PHD finger of NURF couples histone H3 lysine 4 trimethylation with chromatin remodelling. Nature 2006, 442:86-90

25. Okabe I, Bailey LC, Attree O, Srinivasan S, Perkel J, Laurent BC, Carlson M, Nelson DL, Nussbaum RL: Cloning of human and bovine homologs of SNF2/SWI2: a global activator of transcription in yeast $\mathrm{S}$. cerevisiae. Nucl Acids Res 1992, 20:4649-4655

26. Alpaugh ML, Tomlinson JS, Shao ZM, Barsky SH: A novel human xenograft model of inflammatory breast cancer. Cancer Res 1999, 59:5079-5084

27. Tomlinson JS, Alpaugh ML, Barsky SH: An intact overexpressed E-cadherin/alpha,beta-catenin axis characterizes the lymphovascular emboli of inflammatory breast carcinoma. Cancer Res 2001, 61:5231-5241

28. Barsky SH: Myoepithelial mRNA expression profiling reveals a common tumor suppressor phenotype. Experimental and Molecular Pathology 2003, 74:113-122, 2003

29. Shimada M, Nakanishi M: DNA damage checkpoints and cancer. J Mol Hist 2006, 37:253-260

30. Sherr CJ: Cancer cell cycles. Science 1996, 274:1672-1677

31. Mohamed MA, Greif PA, Diamond J, Sharaf O, Maxwell P, Montironi R, Young RA, Hamilton PW: Epigenetic events, remodelling enzymes and their relationship to chromatin organization in prostatic intraepithelial neoplasia and prostatic adenocarcinoma. BJU Int 2007, 99:908-915

32. Ito T, Bulger M, Pazin MJ, Kobayashi R, Kadonaga JT: ACF, an ISWI-containing and ATP-utilizing chromatin assembly and remodeling factor. Cell 1997, 90:145-155

33. Osley MA, Tsukuda T, Nickoloff JA: ATP-dependent chromatin remodeling factors and DNA damage repair. 
Mutat Res 2007, 618:65-80

34. Lazzaro M A, Picketts D J: Cloning and characterization of the murine Imitation Switch (ISWI) genes: differential expression patterns suggest distinct developmental roles for Snf2h and Snf21. J Neurochem 2001, 77:1145-1156

35. Lazzaro MA, Pepin D, Pescador N, Murphy BD, Vanderhyden BC, Picketts DJ: The imitation switch protein SNF2L regulates steroidogenic acute regulatory protein expression during terminal differentiation of ovarian granulosa cells. Mol Endocrinol 2006, 20:2406-2417

36. Ye Y, Tian H, Lange AR, Yearsley K, Robertson FM, Barsky SH: The genesis and unique properties of the lymphovascular tumor embolus are because of calpainregulated proteolysis of E-cadherin. Oncogene, epub ahead of print 14 May 2012, DOI 10.1038/onc.2012.180

37. Tsukiyama T, Palmer J, Landel CC, Shiloach J, Wu C: Characterization of the imitation switch subfamily of ATPdependent chromatin-remodeling factors in Saccharomyces cerevisiae. Genes Dev 1999, 13:686-697

38. Downs JA, Allard S, Jobin-Robitaille O, Javaheri A, Auger A, Bouchard N, Kron SJ, Jackson SP, Cote J: Binding of chromatin-modifying activities to phosphorylated histone H2A at DNA damage sites. Mol Cell 2004, 16:979-990

39. Levine AJ: p53, the cellular gatekeeper for growth and division. Cell 1997, 88:323-331

40. Chan TA, Hermeking H, Lengauer C, Kinzler KW, Vogelstein B: 14-3-3 Sigma is required to prevent mitotic catastrophe after DNA damage. Nature 1999, 401:616-620

41. Varga-Weisz PD, Wilm M, Bonte E, Dumas K, Mann M, Becker PB: Chromatin-remodelling factor CHRAC contains the ATPases ISWI and topoisomerase II. Nature 1997, 388:598-602

42. Kwon HS, Lim HW, Wu J, Schnölzer M, Verdin E, Ott M: Three novel acetylation sites in the foxp3 transcription factor regulate the suppressive activity of regulatory $\mathrm{T}$ cells. J Immunol 2012, 188:2712-2721

43. Beutler B, Jiang Z, Georgel P, Crozat K, Croker B, Rutschmann S, Du X, Hoebe K: Genetic analysis of host resistance: Toll-like receptor signaling and immunity at large. Annu Rev Immunol 2006, 24:353-389. 